\title{
Na Beira dos Rios, a Margem da Cidade: Configurações do Trabalho Feminino na Cidade de Teresina-PI (década de 1970)
}

Yasminn Escórcio Meneses da Silva ${ }^{I}$

Marcelo de Sousa Neto ${ }^{I I}$

Resumo: O presente artigo discute as novas configurações de trabalho na cidade de Teresina, por meio da análise do trabalho das lavadeiras de roupa dos rios Parnaíba e Poti, rios que atravessam a cidade, bem como o crescente número dessas mulheres que se dedicavam a essa tarefa, como forma de garantir seu sustento e de sua família. Observou-se que o crescimento do quantitativo de mulheres que se dedicavam a essa atividade esteve relacionado a um forte processo migratório e de crescimento populacional da cidade. O recorte temporal da pesquisa, delimitado como a década de 1970, foi definido por corresponder ao período em que Teresina experienciou um forte processo de transformação de espaços, no interior de uma política de construção de grandes obras, financiadas pelo estado, modificando as formas e oportunidades de trabalho na cidade. Desta forma, se pôde verificar a alteração no cotidiano de trabalho das lavadeiras que, com a criação das lavanderias comunitárias, foram realocadas para um espaço físico dedicado ao tipo de atividade, motivado também pelo interesse de retirá-las das margens dos rios. Para essa pesquisa, além do uso de fontes hemerográficas, foi utilizado o diálogo com as fontes orais por meio de entrevistas, baseadas na metodologia da História Oral. Dentro desse contexto, foi possível observar como a cidade se desenvolveu por meio de trabalhos informais, a exemplo das lavadeiras, que movimentaram a economia e o crescimento da capital.

Palavras-chave: História, Cidade e Trabalho.

\section{In the Margin of the Rivers, the Margin of the City: Women's Work Settings In The City of Teresina-PI (1970's)}

Abstract: The present article discusses the new work configurations in the city of Teresina, by analyzing the work of the women who washed clothes in the rivers Parnaíba and Poti, rivers that cross the city, as well as the increasing number of women who were engaged in this work, as a way to guarantee their livelihood and their family. It was observed that the growth of the number of women engaged in this activity was related to a strong migratory process and population growth of the city. The temporal cut of the research, delimited as the 1970s, was defined to correspond to the period in which Teresina experienced a strong process of transformation of spaces, within a policy of construction of great works, financed by the state, modifying the forms and opportunities in the city. In this way, it was possible to verify the change in the daily work of the washerwomen who, with the creation of community laundries, were relocated to a physical space dedicated to the type of activity, motivated also by the interest to remove them from the river banks. For this research, besides the use of hemerographic sources, the dialogue with the oral sources was used through interviews, based on Oral History methodology. Within this context, it was possible to observe how 


\title{
NA BEIRA DOS RIOS, A MARGEM DA CIDADE: CONFIGURAÇÕES DO TRABALHO FEMININO NA CIDADE DE TERESINA-PI (DÉCADA DE 1970)
}

\author{
YASMINN ESCÓRCIO MENESES DA SILVA \\ MARCELO DE SOUSA NETO
}

the city developed through informal jobs, like the women who washed clothes, that moved the economy and the growth of the capital.

Keywords: History, City and Job.

Artigo recebido em 10/03/2019 e aprovado em 28/05/2019.

\section{Introdução}

Discutir o contexto socioeconômico que envolve as formas de acesso ao trabalho na cidade de Teresina, e de forma especial ao trabalho das lavadeiras de roupas da cidade, requer a atenção de se perceber o contexto histórico em que na capital propagavam-se pensamentos e ações ancorados no discurso da busca do progresso ${ }^{\text {III }}$. Seus efeitos refletiram-se não somente em conformação territorial, mas também sobre sua organização social, resultando em uma cidade que se transformava, no que diz respeito às maneiras de viver e conviver numa cidade em transformação.

Teresina, quando de sua criação em 1852, foi planejada como capital do Piauí e nasceu desde cedo junto à pobreza e o desejo de modernidade ao seu lado ${ }^{\mathrm{IV}}$. A região escolhida para a capital inseriu-se nas estratégias econômicas do estado para desenvolver a Província, em que se esperava um melhor aproveitamento da navegabilidade da bacia do Parnaíba, aliada ao controle do comércio local e uma melhor comunicação entre as províncias e com o restante do mundo ${ }^{\mathrm{V}}$.

Em razão da criação da nova capital, as migrações tornaram-se frequentes, acentuandose ainda mais no início de século XX. Uma cidade ainda jovem e com ares rurais começa a crescer desordenada, de forma estrutural e econômica, pois não havia emprego nem moradias adequadas para uma parcela significativa de sua população, cuja maioria era composta por pessoas pobres, que iam para o centro urbano em busca de melhores condições de vida ${ }^{\mathrm{VI}}$. A esse respeito, observa Castelo Branco,

\begin{abstract}
Esses números tendiam a crescer periodicamente, devido às secas que assolavam os Estados nordestinos. A cidade tornava-se polo de atração para as massas imigrantes, que saiam de suas terras em busca de melhores condições de vida [...] As possibilidades de trabalho para essas massas de pessoas, que viviam sempre perseguidas pela necessidade, eram restritas. A cidade contava com poucas indústrias, e o setor de serviços era por demais pequeno para absorver toda a mão-de-obra disponível. ${ }^{\mathrm{VII}}$
\end{abstract}

Desse modo, a cidade se constituiu como espaço possível para a sobrevivência e horizonte de melhorias em variados aspectos para esses migrantes, mesmo que de maneira marginalizada $^{\mathrm{VIII}}$, ou seja, com trabalhos informais e não regulamentados pelo poder público.

Entre essas práticas marginais ou informais de inserção no mercado de trabalho da cidade, para as mulheres, o trabalho como lavadeiras surgiu como alternativa viável, prática observada por todo o século XX, estimulando o desenvolvimento da presente pesquisa. No entanto, para aprofundar o conhecimento acerca da condição social das lavadeiras de roupas em 


\title{
NA BEIRA DOS RIOS, A MARGEM DA CIDADE: CONFIGURAÇÕES DO TRABALHO FEMININO NA CIDADE DE TERESINA-PI (DÉCADA DE 1970)
}

\author{
YASMINN ESCÓRCIO MENESES DA SILVA \\ MARCELO DE SOUSA NETO
}

Teresina, tendo como ambiente para executar suas tarefas os rios Poti e Parnaíba, é pertinente, sobretudo para a historiografia brasileira e piauiense, atentar a abordagem do tema, com ênfase na inserção feminina no trabalho por meio da configuração do espaço urbano. A análise do espaço físico no qual as lavadeiras trabalhavam, tanto nos rios quanto nas lavanderias comunitárias, remetem-nos a uma observação atenta sobre o espaço físico, urbano e ambiental da cidade.

Como fontes analisadas, foram utilizados dados estatísticos, resultantes dos Censos Demográficos do Instituto Brasileiro de Geografia e Estatística - IBGE, entrevistas baseadas na metodologia da História Oral, além da utilização de variadas matérias dos jornais que circularam na cidade durante o período recortado pela pesquisa, entre eles o Jornal $O$ Dia, Jornal Do Piauí e Jornal $O$ Estado. Outras fontes relevantes para a fundamentação da pesquisa foram as mensagens dos órgãos do governo, tanto estadual quanto municipal, direcionadas ao poder Legislativo.

\section{De migrantes a "construtores" da cidade em movimento}

A cidade de Teresina, na década de 1970, encontrou-se em meio a variadas intervenções no seu ambiente territorial. Esse processo idealizador do progresso - que tende a embelezar e higienizar a cidade com mudanças arquitetônicas - acabou por reconfigurar e transformar a vida e o cotidiano dos moradores da capital.

A intenção de organizar e projetar a cidade permeia o imaginário da capital desde o século XIX, cuja ideia baseava-se em disciplinar seus habitantes, tanto no que se refere ao controle social, como em termos de trabalho, para manter uma conformidade com a cidade em progresso. Logo, ao mudar seus hábitos os seus citadinos deveriam por consequência se adequar a tal. E essa perspectiva refletia-se em todos os âmbitos da sociedade teresinense, muito além de apenas estrutural, estendia-se ao comportamento.

Entretanto, o projeto de embelezamento e modernização da capital era obstruído por uma realidade bem diferente e de difícil correção. Com as crescentes migrações do interior do Estado e estados vizinhos para Teresina, a população da capital cresceu desordenadamente. Essa desordem se refletiu na dificuldade de acesso a bens e direitos, a exemplo da moradia, emprego, educação e saúde, problemas identificados por Maria Mafalda Baldoíno Araújo, já nas primeiras décadas do século XX, ao destacar,

\begin{abstract}
O crescimento populacional na capital do Piauí, advindo das migrações, não foi acompanhado por oportunidades de trabalho. Parte dessa população não tinha sequer condições físicas para trabalhar e o número de mortes não era pequeno, em decorrência das doenças e da miséria na qual vivia. Apenas uma parte dessa população vivia do trabalho casual [...]. ${ }^{\mathrm{IX}}$
\end{abstract}

Por todo o século XX, o número de migrantes em direção a Teresina apenas crescia, ampliando, sobremaneira, seu quantitativo de habitantes. Em 1970, segundo dados do IBGE, a capital correspondia a um total de 220.487 habitantes, dos quais grande parcela de migrantes que constituíam os segmentos mais pobres da sociedade teresinense, característica também percebida por Araújo nos primeiros anos da República, ao observar que,

A cidade de Teresina inchava mais que crescia, com "levas de migrantes" procedentes tanto do interior do Piauí quanto de outras províncias do Nordeste, com destino à Amazônia, e que por aqui ficavam, em virtude de não terem 


\section{NA BEIRA DOS RIOS, A MARGEM DA CIDADE: CONFIGURAÇÕES DO TRABALHO FEMININO NA CIDADE DE TERESINA-PI (DÉCADA DE 1970)}

\section{YASMINN ESCÓRCIO MENESES DA SILVA \\ MARCELO DE SOUSA NETO}

condições de prosseguir viagem. Esse fato provocou a multiplicação da pobreza na cidade. A massa de migrantes, pobres desempregados, acometida pela fome, doenças e miséria atingia Teresina $[\ldots]{ }^{\mathrm{X}}$

Algumas dessas características mantiveram-se mesmo com o consequente desenvolvimento e crescimento da cidade. $O$ conflito urbano e rural ainda perdurou promovendo ações comuns aos trabalhadores da capital, como o costume de se lavar roupas nas margens dos rios, ou ainda a criação de animais como: galinha, porco e vacas pelos arredores da cidade, com livre circulação nas vias públicas, sem controle e higiene.

A migração foi um fato que muito agravou os problemas sociais que já existiam na capital. Com o êxodo rural, a capital passa a receber uma grande quantidade de migrantes e, estruturalmente, ainda não estava preparada para tal situação, e como confirma Nascimento, que a cidade "ao atrair novos moradores vindos de outros cantos do Piauí, e também de Estados vizinhos, atingidos pela seca prolongada, pela expulsão do campo, pelo desejo de dar aos filhos uma vida melhor do que aquela vivida por cada trabalhador rural que chegava Teresina"XI, contrastando com a realidade que se apresentava. Soma-se a esse fator a busca por empregos, que como exemplo, encontramos no objeto da pesquisa, as lavadeiras, que ao se deparar com a cidade grande, cheia de novidades, mas carente de vagas em empregos de qualidade e formal, direcionam-se a atividades mais informais, onde a possibilidade de renda era garantida com mais urgência.

Figura 1: O drama da imigração

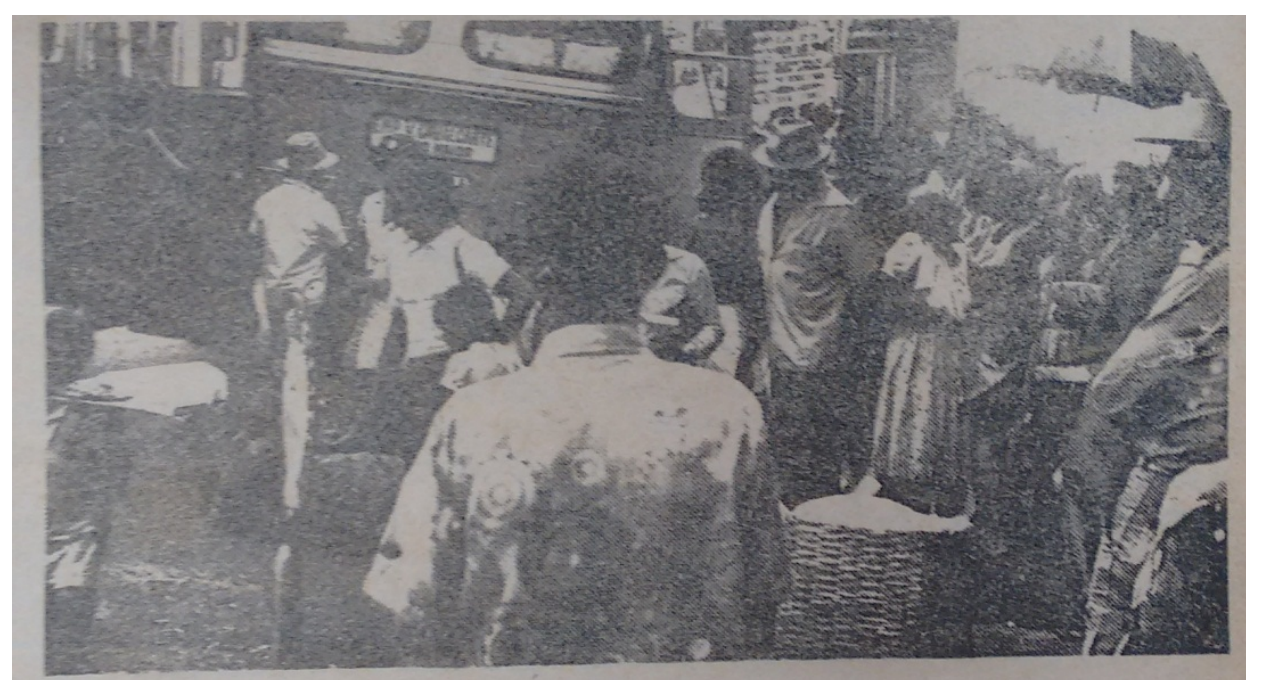

Fonte: Jornal Estado. Arquivo Público do Estado do Piauí - Casa Anísio Brito. 1975

O processo migratório foi um fato que chamou muito a atenção de críticos, jornalistas e outros intelectuais do período estudado. Na imagem acima, é mostrada a chegada de homens, mulheres e crianças na Praça Saraiva, que se localizava na região central da capital e onde funcionava uma pequena rodoviária para aqueles que chegavam e/ou saiam da capital.

Nos jornais pesquisados, o uso de imagens era também recorrente, o que caracteriza, de fato, uma preocupação de parte dos habitantes locais para com a situação social em que se 


\title{
NA BEIRA DOS RIOS, A MARGEM DA CIDADE: CONFIGURAÇÕES DO TRABALHO FEMININO NA CIDADE DE TERESINA-PI (DÉCADA DE 1970)
}

\author{
YASMINN ESCÓRCIO MENESES DA SILVA \\ MARCELO DE SOUSA NETO
}

deparavam as pessoas que chegavam e não encontravam emprego e conforto. É percebido isso através das inúmeras matérias nos jornais diários que circulavam na capital durante o período, como exemplo na matéria publicada pelo Jornal Estado, em 1975, que colocava em destaque,

\begin{abstract}
Mais da metade da população de Teresina é migrante em potencial. A maioria das famílias residentes na capital são procedentes das diversas cidades do interior do Estado e de outras unidades da Federação, predominando o Maranhão, o Ceará, Paraíba e Pernambuco. Em 1960, nossa capital contava com 145 mil habitantes. Hoje possui cerca de 340 mil. Dezenas de migrantes, chegam diariamente na praça Saraiva, vindo para Teresina tentar melhoria de vida. Não existe oferta de trabalho nem as indústrias vem. Eis o drama que vem constituindo um dos graves problemas sociais na metrópole piauiense. XII
\end{abstract}

A capital, até então, já se mostrava em desenvolvimento, mas não oferecia suporte suficiente para todas as classes sociais que a ela recorriam como nova moradia, principalmente as mais pobres, tão tal que a necessidade de empregos se torna mais frequente, denunciada na matéria pelo fato de haver poucas indústrias para comportar a grande massa que estava a mercê do desemprego, e soma-se a ainda o fator habitacional, acarretando o aumento das favelas na periferia da cidade, isso porque a popularização de conjuntos habitacionais só começa a ser desenvolvida a partir de 1975, com a construção de conjuntos como o Itararé. ${ }^{\text {XII }}$

Em uma cidade de limitadas oportunidades de renda, torna-se oportuno discutir o fenômeno da migração para a capital, fator importante para se compreender a crescente presença feminina nos rios como forma de garantir acesso a alguma renda, não encontrada por meio do trabalho formal. Assim, com suas expectativas frustradas, homens e mulheres se submetiam aos trabalhos mais árduos, que exigiam um esforço físico que, por vezes, excedia ao que seu corpo poderia aguentar.

Os homens eram aproveitados, principalmente, no ramo da construção civil, ao passo que as mulheres se empregavam em trabalhos domésticos, constituindo os dois eixos que mais empregavam aqueles que não tinham estudos e condições financeiras razoáveis para se manter. É a partir de situações como essa que as mulheres começam a estender seus afazeres domésticos para além da porta de casa como meio de sustento próprio e de sua família. ${ }^{\text {XIV }}$

Além disso, Teresina foi palco de inúmeras intervenções em sua estrutura física com o intuito de se modernizar estruturalmente, assim como ocorreu em Recife e no Rio de Janeiro nos anos iniciais da República. Todavia, essa ideia só foi de fato concretizada através dos governos militares (1964-1985) que disponibilizaram movimentação de grandes recursos aos estados com o intuito de produzir um efeito de desenvolvimento ao país, por meio do que ficou conhecido como período do "Milagre Econômico", promovido a custas do severo endividamento do Estado brasileiro. ${ }^{\mathrm{XV}}$

Desta forma, entende-se que Teresina sentiu fortemente os efeitos da política desenvolvimentista dos governos militares. A capital do estado se tornou um verdadeiro "canteiro de obras" que impulsionou as construções de embelezamento da cidade e estimulou as mudanças estruturais no espaço urbano. Durante esse período, o governo do Estado e Município acreditavam que, por meio das intervenções nas estruturas físicas da capital, seria possível tirar o Piauí da miséria e do atraso social e econômico, levantando a autoestima dos moradores ${ }^{\mathrm{XVI}}$.

No entanto, à medida que a capital se desenvolvia e se adaptava aos modelos de metrópole, por meio do projeto de modernização do espaço urbano, a população mais 


\title{
NA BEIRA DOS RIOS, A MARGEM DA CIDADE: CONFIGURAÇÕES DO TRABALHO FEMININO NA CIDADE DE TERESINA-PI (DÉCADA DE 1970)
}

\author{
YASMINN ESCÓRCIO MENESES DA SILVA \\ MARCELO DE SOUSA NETO
}

carente era submetida a condições precárias de vida, em decorrência de um reordenamento que a excluía e colocava em conflito a "cidade dos sonhos" e a "cidade vivida e executada",XVII.

De acordo com o historiador Alcides Nascimento, Teresina cresceu sob o signo do moderno. A capital planejada, construída em local centralizado do Estado, possibilitaria um crescente desenvolvimento social e econômico devido às condições de navegabilidade do rio Parnaíba que, até o momento, eram favoráveis ${ }^{\mathrm{XVIII}}$.

Apesar das inúmeras possibilidades de crescimento e progresso, auxiliadas pelo "milagre econômico" e a efervescência de novas empresas, o que se constata é que essas possibilidades não lograram êxito pela incapacidade do Estado e da capital para gerir a manutenção e criação de empregos ou de garantir a qualidade de vida dos moradores e das pessoas que migravam, agravando ainda mais a situação social da cidade.

\section{Dos rios para a lavanderia: novas configurações, novos significados}

Na primeira metade da década de 1970, a representação que se fazia da capital Teresina era de uma cidade que se modernizava, em constante transformação, e que traria o Piauí ao patamar semelhante as grandes capitais do país, como se pode observar por meio dos periódicos da época ${ }^{\mathrm{XIX}}$. Esse imaginário se prolongou, pois, com as obras de embelezamento, Teresina passou a ser cada vez mais procurada e vivida como uma cidade que possibilitaria uma melhor condição de vida e crescimento profissional, como foi destacado anteriormente.

Esses aspectos têm caráter relevante, visto que foi através do crescimento e da modernização da capital que o trabalho das lavadeiras nos rios Parnaíba e Poti, passou a ser modificado, ressignificando essa profissão e elencando novas características no que tange ao espaço físico do labor, pois reconfigurava uma forma de emprego já habituada em modelos passados, baseando-se em fatores de salubridade e estética.

Neste momento, tanto para homens quanto mulheres, vindos ou não do interior, poucas eram as saídas. A construção civil foi um ramo que cresceu muito no período, favorecida pelas constantes intervenções estatais e a crescente industrialização que cercavam as metrópoles brasileiras. Como meio de sustento, homens e mulheres se dedicavam a atividades que pudessem ser mais básicas de se realizar, configurando formas de trabalhos informais e necessários para situações na qual se encontravam.

Nesse cenário, a atividade de lavagens de roupas nos rios foi uma saída possível para tantas mulheres que, sem qualificação profissional, não conseguiam se inserir no mercado formal de trabalho, como se pode observar por meio dos depoimentos de muitas destas e que se procurou dar destaque na pesquisa.

No relato da senhora Francisca Maria Pereira Dias, ao chegar a capital, uma alternativa para aumentar o lucro em casa foi trabalhar em casas de famílias e lavar roupas no rio. Seu marido, conforme descrito na entrevista, já estava trabalhando como servente de pedreiro, mas a renda ainda assim ficava comprometida, pois, como relembra, 


\title{
NA BEIRA DOS RIOS, A MARGEM DA CIDADE: CONFIGURAÇÕES DO TRABALHO FEMININO NA CIDADE DE TERESINA-PI (DÉCADA DE 1970)
}

\author{
YASMINN ESCÓRCIO MENESES DA SILVA \\ MARCELO DE SOUSA NETO
}

ele aceitou que trabalhasse também pra ajudar, logo arranjei trabalho, trabalhava em casa de família. E aos sábados eu também trabalhava fazendo uns lavados de roupa, lavando e passando roupa, para outras casas. Lavava as roupas no rio, era ali nas margens do rio, do rio Parnaíba, lá tinha umas pedras, aí se juntavam muitas mulheres que iam lavar as roupas de suas patroas e às vezes a de sua família mesmo. Mesmo assim o dinheiro meu, mais o de meu marido dava mal pra comer, nesse tempo tudo de comer era muito caro $[\ldots]^{\mathrm{XX}}$.

Observando por essa perspectiva, lavar roupas em rios é um meio de trabalho que garante às mulheres a participação no crescimento econômico da própria renda familiar, uma vez que havia a necessidade de se manter, sendo assim, tanto para os moradores quanto para aqueles que vieram de outras comunidades, era uma solução mais prática para continuar sua sobrevivência na capital.

Dentre os variados fatores que levavam as mulheres de camadas sociais menos abastadas a estender suas tarefas domésticas até a beira de um rio, estão o fato de não haver água encanada em suas casas; a insuficiência para armazenamento da água, o abastecimento irregular dos chafarizes, quando ainda funcionavam; e principalmente, para a obtenção do lucro para complementar a renda de casa, lavando em muitas quantidades e para várias famílias.

A necessidade como força motriz para a busca de alternativas de renda para o sustento da família representa aspecto também destacado por Maria Izilda de Matos, que entende,

O esforço para trazer à família recursos monetários marginais, vitais em caso de crise, sempre acarretou um aumento da atividade feminina, levando as mulheres a reproduzir ocupações desenvolvidas nos quadros domésticos, como lavar, passar e engomar, que passaram a constituir para as mulheres pertencentes aos estratos sociais mais baixos uma opção de ocupação remunerada, impondo-lhes uma jornada de trabalho ampla extensão de sua própria atividade doméstica e com míseros ganhos. ${ }^{\mathrm{XI}}$

Em Teresina, a vida das lavadeiras nos rios Poti e Parnaíba não foi fácil. Juntamente com a discriminação pela profissão - materializada pela opinião de jornalistas e sanitaristas - havia ainda as condições físicas, não somente dos rios, mas das condições sanitárias e insalubres das lavagens. Jornais do período consideravam as lavadeiras como um problema para além da saúde pública, já que se observava também dentro de uma questão moral, em uma sociedade apegada a hábitos regulados e por meio de padrões estabelecidos pela modernidade, onde o estético e o asséptico são valorizados, como é possível analisar na matéria publicada no Jornal Estado do Piauí, em 1971:

O façam, mas sem o preconceito de que a natural e higiênica nudez semivetada das nossas lavadeiras agride a pudica alheia. Num mundo ostensivo e obscenamente despido a nudez sem malícia das lavadeiras do Parnaíba não fere a sensibilidade visual de ninguém. Já se disse que "todo grande rio é triste" o Parnaíba o é. Basta contemplá-lo com os olhos d'alma, para sentir sua murmurante tristeza, geradora das nossas nostalgias. E são justamente as lavadeiras com a sua tagarelice em voz alta com o riso aberto e gargalhadas 


\title{
NA BEIRA DOS RIOS, A MARGEM DA CIDADE: CONFIGURAÇÕES DO TRABALHO FEMININO NA CIDADE DE TERESINA-PI (DÉCADA DE 1970)
}

\author{
YASMINN ESCÓRCIO MENESES DA SILVA \\ MARCELO DE SOUSA NETO
}

estridentes, a nota alegre na contagiante tristeza dos rios. Que se resolva o problema sem o propósito proibitivo do despretensioso diálogo canoeiro, do vareiro, do passador com as lavadeiras do Parnaíba, que a Previdência Social deva colocar sob sua égide. XXII

De acordo com a matéria, nota-se a necessidade da criação e construção de lavanderias, como espaços físicos adequados às lavagens de roupas, retirando as lavadeiras das margens dos rios. Especialmente nessa matéria, vemos o pedido do jornalista ao se referir às lavadeiras do rio Parnaíba, ao elencar que,

A instalação de lavanderias, sendo da alçada dos poderes públicos, governo ou prefeitura, não apresenta maiores dificuldades, dependendo apenas, de limitados recursos financeiros. Para ambos há soluções exequíveis, valendo a pena enfrenta-los. ${ }^{\text {XIII }}$

$\mathrm{Na}$ matéria, denuncia-se a falta de assistência as lavadeiras do rio Parnaíba, condição semelhante a todas as lavadeiras da cidade, e que encontrou um ponto de mudança com a construção de uma lavanderia comunitária, mas que ainda assim não extinguiram as dificuldades enfrentadas por essas trabalhadoras.

Dentro dessa necessidade, exibida por meio das opiniões dos jornalistas, é que começam a surgir as primeiras discussões em torno das lavadeiras e de seus espaços de trabalho, os rios da cidade. Além disso, a questão também se colocava por meio das constantes críticas que se dirigiam aos governantes em relação ao sanitarismo que a cidade àquele momento vivenciava, tal qual a modernização de espaços, como a reforma do Mercado Velho, alargamento de avenidas, construções de habitações populares com o mínimo de saneamento e higiene. Foi então que, a partir da visibilidade que as condições das lavadeiras alcançavam nos discursos da impressa local, o Serviço Social do Estado - SERSE, levou a pauta para discussão com o governador.

O governador Alberto Tavares Silva está empenhado na construção de diversas lavanderias nos bairros de Teresina, conforme informação de fonte do Serviço Social do Estado. O chefe do Executivo atende a uma recomendação do Serviço Especial de Saúde Pública, que, através de pesquisas descobriu que a grande incidência de tuberculose nos bairros, principalmente nas mulheres, é determinada pelo fato de elas ficarem à beira do rio e, posteriormente, subirem para seus casebres, sofrendo uma mudança brusca de temperatura. XXIV

O discurso sanitarista reagiu sobre o ofício dessas mulheres. Não somente como um meio de oferecer um lugar salubre e adequado às lavadeiras de roupas, o discurso pretendia ainda afastá-las da visão central da cidade, segundo a qual os rios passavam a bela imagem para turistas e visitantes. Manter os rios limpos e "saudáveis" era um desejo dos administradores da capital. Afastar as lavadeiras da beira do rio para um local adequado para a realização de seu trabalho foi um projeto pensado com o intuito de oferecer melhor condição ao labor dessas mulheres e ainda reduzir os problemas sociais. ${ }^{\mathrm{XXV}}$

Ademais, havia o problema caracterizado nos jornais como promiscuidade, que surgia em função das mulheres ficarem com seus corpos molhados e expostos ao sol, 


\title{
NA BEIRA DOS RIOS, A MARGEM DA CIDADE: CONFIGURAÇÕES DO TRABALHO FEMININO NA CIDADE DE TERESINA-PI (DÉCADA DE 1970)
}

\author{
YASMINN ESCÓRCIO MENESES DA SILVA \\ MARCELO DE SOUSA NETO
}

em um ambiente público próximo a ruas e avenidas movimentadas, como é descrito na matéria abaixo:

\begin{abstract}
Outro problema visto pelo Serviço Social do Estado foi o da promiscuidade, principalmente porque ficam as mulheres lavando roupas enquanto homens atravessam o rio ou vão ali tomar banho. Segundo fonte da Secretaria de Obras, a primeira lavanderia a ser construída será no bairro Por Enquanto, onde há maior incidência de tuberculose entre lavandeiras. Ontem um funcionário da Secretaria já esteve naquele bairro escolhendo um local. Deverão ainda ser construídas na Piçarra, Matinha e Poty Velho. ${ }^{\text {XXVI }}$
\end{abstract}

Foi nesse contexto em que foi criado o Centro Materno-Infantil e Nutricional, na capital. Inaugurado em maio de 1972, com recursos do Estado, durante a administração de Alberto Tavares Silva, o Centro tinha o propósito de adentrar no projeto de modernização da capital e assim oferecer um ambiente adequado às lavadeiras de roupas que se sujeitavam às margens dos rios de Teresina, desde o amanhecer do dia ao entardecer. Sobre a construção do Centro, assim descrevia periódico da época,

Ao assumir o Governo, o engenheiro Alberto Silva procurou sentir a grande
extensão dos problemas sociais no Piauí, encarregando, assim, o Serviço Social
do Estado - Serse - de uma série de encargos e partindo de uma experiência
pioneira, que rendeu resultados compensadores: a construção do Centro
Materno-Infantil e Nutricional, no bairro Ilhota, visando a realização de um
trabalho de educação global junto à lavandeira e sua família. XXVII

Segundo dados do SERSE, em discurso oficial, a lavanderia envolveu uma comunidade total de 379 pessoas ${ }^{\text {XVVIII }}$. No mesmo ano de sua inauguração, em 1972, já havia 97 lavadeiras cadastradas para os benefícios, que contavam não somente com o espaço físico salubre e adequado, mas também com assistências médica e escolar, dedicadas a elas e aos seus filhos. Na mesma pesquisa, foi constatado que,

Nada menos de 176 lavandeiras na zona Sul de Teresina, $73 \%$ das quais com
renda bruta mensal de 50 cruzeiros. No meio desse grupo existem 54 filhos
com idades que variam entre 0 e a 1 ano; 148 filhos com idade que variam
entre 1 e 5 anos; 288 filhos com a idade de 6 a 15 anos e 410 com mais de 15
anos. [...] Ela revela, baseada no fato de que a maioria dessas mulheres ganha
50 cruzeiros por mês, que a alimentação do grupo não poderia ultrapassar os
limites do arroz, feijão, farinha e café. XXIX

No relato de Dona Rosa Maria da Costa Alves, 83 anos, que, antes de trabalhar na lavanderia do Centro Materno, lavava roupas no rio Poti para manter o sustento de sua família, percebemos como as ações concluídas pelo programa trouxeram qualidade de vida para a lavadeira e seus filhos, na medida em que facilitou seu trabalho, despreocupando-a de possíveis doenças ou desamparo por parte das administrações, e beneficiou-as com suprimentos necessários (alimentar e educacional) nos espaços da lavanderia.

As crianças tinha o local onde colocar. Tinha secretária. A mãe dessa daqui (sua neta, Eloá, que estava lá) [...]. E tinha crechezinha delas. A mãe trabalhando e a creche ali do nosso lado. Ahh! Eu dizendo que o governo num tinha dado. Deu! O prefeito deu a creche [...] pros filho das lavandeiras. Aí as lavandeiras trabalhando e os 'meninozim' dela do lado dela. Os que 


\section{NA BEIRA DOS RIOS, A MARGEM DA CIDADE: CONFIGURAÇÕES DO TRABALHO FEMININO NA CIDADE DE TERESINA-PI (DÉCADA DE 1970)}

\section{YASMINN ESCÓRCIO MENESES DA SILVA MARCELO DE SOUSA NETO}

mamavam elas iam dar amamentação a criança e os que num amamentava dava o alimento. $\mathrm{Xxx}$

O projeto idealizado pelo governador do estado Alberto Tavares Silva (19711975) ainda pretendia estender as lavanderias aos bairros mais pobres de Teresina e também para a cidade de Parnaíba, no litoral piauiense ${ }^{\mathrm{XXI}}$. Isso porque, como afirmou o secretário de saúde Dirceu Arcoverde, através de reportagem no Jornal A Hora, "essa assistência prevê inclusive a distribuição de merenda e a instalação de bibliotecas"XXXII, e ainda diz que "numa segunda etapa a Secretaria de Saúde e Serviço Social do Estado levarão iguais benefícios às lavadeiras residentes em outras áreas da cidade"XXXIII, justificando que o problema maior da relação da lavadeira com a lavanderia é o fato de não ter condições de deixar seus filhos em casa, por isso seria necessário que a lavanderia garantisse as lavadeiras a guarda e segurança das crianças, oferecendo ainda alimentação e apoio educacional.

Com isso, uma melhor condição social, idealizada pelo desejo de modernização e pelo discurso sanitarista, deu às lavadeiras de roupas do rio Poti um novo ambiente de trabalho, limpo, confortável e adequado para o exercício de sua profissão.

Figura 2: As lavadeiras do rio Poti antes da criação do Centro Materno-Infantil

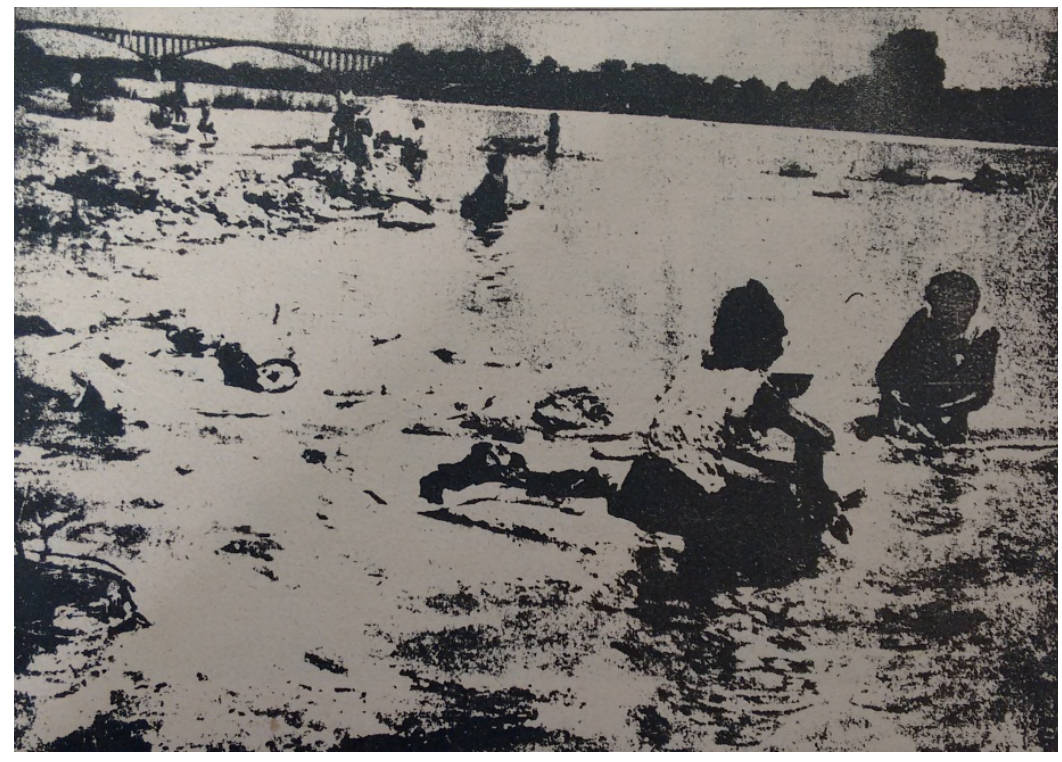

Fonte: Jornal O Estado. Arquivo Público do Estado do Piauí - Casa Anísio Brito. 1975

Mas os limites da lavanderia recém-inaugurada logo tornaram-se evidentes. Enquanto a lavanderia beneficiava parcela das lavadeiras do rio Poti, as mulheres que lavavam roupas no cais do Parnaíba reclamavam de não ter a mesma assistência e usufruto de um espaço adequado ao seu labor, como se pode observar por meio do fragmento a seguir: 


\title{
NA BEIRA DOS RIOS, A MARGEM DA CIDADE: CONFIGURAÇÕES DO TRABALHO FEMININO NA CIDADE DE TERESINA-PI (DÉCADA DE 1970)
}

\author{
YASMINN ESCÓRCIO MENESES DA SILVA \\ MARCELO DE SOUSA NETO
}

Para Dona Raimunda Ferreira de Araújo a lavagem de roupa no rio Parnaíba, além de se constituir um perigo constante, é também um meio de fazer com que as roupas fiquem mais encardidas que limpas. Disse ela que depois das enchentes já perdeu grande número de peças de roupas, que as "patroas" exigem indenização. "Se a gente não paga elas descontam no ordenado, então fica a mesma coisa. As lavadeiras do Poti têm mais sorte do que nós porque lá tem a lavanderia do governo e nós não temos mais nem sol para secar a roupa". As declarações de Dona Raimunda foram prestadas ontem e ela indicava que as pessoas de Teresina não gostam muito de lavandeira. Para elas só vão as melhores peças do vestuário, mas roupa comum é lavada mesmo no Parnaíba, onde durante esse período muito problema existe para importunar as profissionais. XXXIV

Pelo fragmento do periódico, publicado quase dois anos após a inauguração da lavanderia da Ilhotas, é possível perceber que a iniciativa pioneira, mesmo tendo sido construída outra seguindo o mesmo padrão no bairro Primavera, Zona Norte da Capital, não foi suficiente para sanar as necessidades da cidade, e não ganhou continuidade nas outras regiões. Após a construção da primeira lavanderia do Centro Materno-Infantil e Nutricional, a cidade continuou a se transformar, a ganhar novas construções. No entanto, a atenção dispensada ao trabalho das lavadeiras limitava-se as estruturas disponibilizadas pelo Centro Materno, que não atendia a demanda do grande número de lavadeiras, dispersas por toda a capital.

Neste cenário de esquecimento, para as lavadeiras do rio Parnaíba, o cais continuava a ser seu lugar de trabalho. O fato de não disporem do mesmo conforto e segurança que as lavadeiras do rio Poti, causavam uma série de transtornos para estas profissionais, agravadas pelas cheias do rio Parnaíba, a exemplo da cheia de 1974, que acarretou grandes problemas devido a perca de peças, causadas pela forte correnteza, e pelo tempo constantemente nublado, tornando mais longo o tempo necessário para secar as roupas lavadas no cais.

Existia também a questão da distância entre a lavanderia comunitária, o rio Parnaíba e a moradia dessas mulheres. Mesmo considerando que a cidade já contava com uma frota de transporte coletivo, o custeio das passagens consumiria o parco lucro das lavagens, tornando inviável para as lavadeiras que moravam próximo do rio Parnaíba se direcionarem para o bairro Ilhotas ou Primavera, onde se localizavam os Centros Materno.

No recorte em estudo, identificamos apenas o funcionamento de dois Centros Maternos, um localizado no bairro Ilhotas, zona sul, e outro no bairro Primavera, zona norte, tendo como estrutura a mesma, e atingindo o mesmo público. Somente a partir do ano de 1982, se pode perceber a iniciativa da prefeitura de Teresina na construção de outras lavanderias baseada no projeto do governo do Estado. Até então, as lavadeiras que não tinham acesso a lavanderia do Centro Materno-Infantil e Nutricional, sobretudo as que moravam próximo ao rio Parnaíba, continuavam a sua sina de abandono por parte dos poderes públicos e da crítica por parte da cidade que aproveitava seus serviços.

\section{Considerações finais}

Cadernos do Tempo Presente, São Cristóvão-SE, v. 10, n. 01, p. 52-66, jan./jul. 2019|

http://www.seer.ufs.br/index.php/tempo 


\title{
NA BEIRA DOS RIOS, A MARGEM DA CIDADE: CONFIGURAÇÕES DO TRABALHO FEMININO NA CIDADE DE TERESINA-PI (DÉCADA DE 1970)
}

\author{
YASMINN ESCÓRCIO MENESES DA SILVA \\ MARCELO DE SOUSA NETO
}

Em meio a seu cotidiano de trabalho, os habitantes das cidades também constroem sociabilidades outras que demarcam sua relação com o espaço urbano, na qual coexistem afetividades e tensões para com as diversas relações constituídas por eles no interior da cidade.

No cotidiano de trabalho de nossas personagens de estudo, as lavadeiras dos rios de Teresina, em seu ritmo diário de casa para os rios, dos rios para casa, em um caminho aparentemente imutável, por meio de seu olhar, nos permitiram encontrar uma cidade em constante transformação. Assim, tornou-se possível um encontro narrativo com essa cidade das lavadeiras, cidade aparentemente invisível, mas que, como tantas outras cidades que coexistem no interior de uma mesma cidade, são tantas vezes reinventadas e ressignificadas.

A reconfiguração de um espaço dentro da cidade modifica o cotidiano de seus moradores, atribuindo-lhes outras "cidades". Na década de 1970, a capital passou por mudanças estruturais, reconfigurando, alterando ou até mesmo criando, dessa forma, novos espaços que antes eram carregados de diversos outros significados. Nessa trajetória de pesquisa, se pôde perceber que os rios já não são mais lugar social e de trabalho das lavadeiras, resultado da intervenção dos poderes públicos, interessados no embelezamento da cidade.

Para as lavadeiras no entanto, a mudança para outro espaço, as lavanderias públicas, a exemplo da lavanderia do Centro Materno-Infantil e Nutricional, significou uma nova configuração de trabalho, com novos espaços, métodos, clientela, segurança, entre outros. No entanto, foram mantidos vínculos afetivos, também transpostos para o novo lugar de trabalho, resultando na permanência de suas identidades, de suas memórias como também construtoras da cidade, que muitas vezes as negou.

Considerando essas características sobre os espaços de sociabilidades e de trabalho das lavadeiras, devemos ponderar que, estruturalmente, mesmo sendo redirecionadas da beira dos rios para as lavanderias comunitárias, os sentimentos não foram destituídos. Sob o ponto de vista do projeto de realocação, foram reconstituídos em novos espaços, que garantissem a elas mais qualidade no trabalho e na vida, além de uma nova estrutura física alinhada ao crescimento da cidade.

\section{Notas}

\footnotetext{
${ }^{\text {I }}$ Mestranda em História pelo Programa de Pós-graduação em História da Universidade Federal do Piauí. Esse texto foi produzido com financiamento da FAPEPI/CAPES.

II Professor Associado da Universidade Estadual do Piauí e do Programa de Pós-graduação em História da Universidade Federal do Piauí.

III A ideia de progresso entendida baseia-se no entendimento de que das inúmeras transformações estruturais que representavam o crescimento da cidade, que seria modernizar-se através de construções significativas e utilitárias para sua população. Dentre esses fatores notamos também, o desejo de uma limpeza dos espaços centrais, higienizando-os, modernizando-os, para garantir um espaço salubre e
} 


\title{
NA BEIRA DOS RIOS, A MARGEM DA CIDADE: CONFIGURAÇÕES DO TRABALHO FEMININO NA CIDADE DE TERESINA-PI (DÉCADA DE 1970)
}

\author{
YASMINN ESCÓRCIO MENESES DA SILVA \\ MARCELO DE SOUSA NETO
}

esteticamente aceito aos moradores e a seus visitantes, bem como o oferecimento de mais oportunidades de empregos. Acerca do processo de transformações por que passou Teresina na década de 1970, ver: FONTINELES, Cláudia Cristina da Silva. O recinto do elogio e da crítica: maneiras de durar de Alberto Silva na memória e na história do Piauí. Teresina: EDUFPI, 2015.

IV NASCIMENTO, Francisco Alcides do. Teresina, a capital que nasceu sob o signo do moderno e da pobreza. In: XXVI SIMPÓSIO NACIONAL DE HISTÓRIA, 26, São Paulo. Anais do XXVI Simpósio Nacional de História. São Paulo: USP, 2011.

V GANDARA, Gercinair Silvério. Rio Parnaíba... Cidades-beira. 2008. 397 f. Tese (Doutorado em História). Universidade de Brasília.

${ }^{\text {VI }}$ CASTELO BRANCO, Pedro Vilarinho. Mulheres plurais. Teresina: Edufpi, 2013. p. 126

VII CASTELO BRANCO, op. cit., p.126.

VIII Entendemos o termo no que se refere tanto a uma relativa parcela da sociedade que estão vivendo na margem da cidade, territorialmente, quanto ao seu poder aquisitivo e simbólico que foge ao padrão imposto pela maior parte da sociedade que vive abastada social, econômica e culturalmente. Para mais informações ver: LIMA, Antônia Jesuíta de. As multifaces da pobreza: forma de vida e representações simbólicas dos pobres urbanos. Teresina: Halley, 2003.

IX ARAÚJO, Maria Mafalda Baldoíno. Cotidiano e pobreza: a magia da sobrevivência em Teresina.

Teresina: Fundação Cultural Monsenhor Chaves, 2010. p. 72.

X ARAÚJO, op. cit., p. 72.

XI NASCIMENTO, Francisco Alcides. O olhar do outro sobre os pobres urbanos de Teresina na década de 1970. In: X ENCONTRO NACIONAL DE HISTÓRIA ORAL, 10, Recife. Anais do X Encontro

Nacional de História Oral Testemunhos: História e Política. Recife: UFPE, 2010, p. 9.

XII O DRAMA da migração. Jornal O Estado. Teresina, ano 705, 27 fev. 1975. p. 10.

XIII FONTINELES, Cláudia Cristina da Silva; SOUSA NETO, Marcelo. Nasce um bairro, renasce a esperança. Teresina: EDUFPI, 2017.

XIV Para mais informações, ver: VIANA, DÉBORA SILVA. Entre o concreto e o etéreo: trabalho e memória dos trabalhadores da construção civil em Teresina na década de 1970. 2013. 281 f. Dissertação (Mestrado em História). Universidade Federal do Piauí, Teresina.

${ }^{\mathrm{XV}}$ FONTINELES, Cláudia Cristina da Silva. O recinto do elogio e da crítica: maneiras de durar Alberto Silva na memória e na história do Piauí. Teresina: EDUFPI, 2015, p. 214.

${ }^{X V I}$ FONTINELES, Cláudia Cristina da Silva. Patrimônios arquitetônicos em Teresina: combates pela memória (década de 1970). Revista História \& Perspectivas, v. 29, n. 54, 2 ago. 2016.

XVII ALMEIDA, Kllaricy Oliveira de. Entre ruínas e arranha-céus: pobreza e modernização no discurso da imprensa escrita teresinense na década de 1970. 2014. 103f. Dissertação (Mestrado em História).

Universidade Federal do Piauí, Teresina.

XVIII NASCIMENTO, Francisco Alcides. O olhar do outro sobre os pobres urbanos de Teresina na década de 1970. In: X ENCONTRO NACIONAL DE HISTÓRIA ORAL, 10, Recife. Anais do X Encontro

Nacional de História Oral Testemunhos: História e Política. Recife: UFPE, 2010, p.1.

XIX FONTINELES, Cláudia Cristina da Silva. Patrimônios arquitetônicos em Teresina: combates pela memória (década de 1970). Revista História \& Perspectivas, v. 29, n. 54, 2 ago. 2016.

XX DIAS, 2011, p. 192 apud VIANA, 2011, p. 192.

${ }^{X X I}$ MATOS, Maria Izilda S. de. Cotidiano e cultura: história, cidade e trabalho. São Paulo: EDUSC, 2002. p. 144.

XXII A MENDINCÂNCIA em Teresina: as lavadeiras do Parnaíba. Estado do Piauí. Teresina, ano 47, n. 1387, 19 ago. 1971. p. 1.

XXIII A MENDINCÂNCIA em Teresina: as lavadeiras do Parnaíba. Estado do Piauí. Teresina, ano 47, n. 1387, 19 ago. 1971. p. 1.

XXIV O GOVERNO construirá lavanderias. Jornal do Piauí. Teresina, ano 20, n. 3.383, 16 jul. 1971. p. 1. XXV SILVA, Yasminn Escórcio Meneses da. "O colorido das lavadeiras": a condição social das lavadeiras de roupas nos rios de Teresina na primeira metade da década de 1970. Monografia (Graduação em Licenciatura Plena em História). Teresina, Universidade Federal do Piauí, 2017.

XXVI O GOVERNO construirá lavanderias. Jornal do Piauí. Teresina, ano 20, n. 3.383, 16 jul. 1971. p. 1. XXVII EDIÇÃO especial. Caderno 2. Jornal O Estado. Teresina, s/n, 6 fev. 1975. p. 6. XXVIII PIAUÍ, 1972. 


\title{
NA BEIRA DOS RIOS, A MARGEM DA CIDADE: CONFIGURAÇÕES DO TRABALHO FEMININO NA CIDADE DE TERESINA-PI (DÉCADA DE 1970)
}

\author{
YASMINN ESCÓRCIO MENESES DA SILVA \\ MARCELO DE SOUSA NETO
}

XXIX FATOS e destaques: Lavandeiras. Jornal a Hora. Teresina, n. 148, 7 abr. 1972. p. 6.
XXX ALVES, Rosa Maria da Costa. Entrevista concedida à Yasminn Escórcio. Teresina, 2017.
XXXI EDIÇÃO especial. Caderno 2. Jornal O Estado. Teresina, s/n, 6 fev. 1975, p. 6.
XXXII FATOS e destaques: Lavandeiras. Jornal a Hora. Teresina, n. 148, 7 abr. 1972. p. 6.
XXXIII FATOS e destaques: Lavandeiras. Jornal a Hora. Teresina, n. 148, 7 abr. 1972. p. 6.
XXXIV A DURA vida das lavadeiras. Jornal O Dia. Teresina, n 3.826, 27/28 jan. 1974. p.5.

\section{Referências Bibliográficas}

ALMEIDA, Kllaricy Oliveira de. Entre ruínas e arranha-céus: pobreza e modernização no discurso da imprensa escrita teresinense na década de 1970. 2014. 103f. Dissertação (Mestrado em História) Universidade Federal do Piauí. Teresina.

ARAÚJO, Maria Mafalda Baldoíno. Cotidiano e pobreza: a magia da sobrevivência em Teresina. Teresina: Fundação Cultural Monsenhor Chaves, 2010.

CASTELO BRANCO, Pedro Vilarinho. Mulheres plurais. Teresina: Edufpi, 2013.

FONTINELES, Cláudia Cristina da Silva. O recinto do elogio e da crítica: maneiras de durar Alberto Silva na memória e na história do Piauí. Teresina: EDUFPI, 2016, p. 214.

Patrimônios arquitetônicos em Teresina: combates pela memória (década de 1970). Revista História \& Perspectivas, v. 29, n. 54, 2 ago. 2016.

FONTINELES, Cláudia Cristina da Silva; SOUSA NETO, Marcelo. Nasce um bairro, renasce a esperança. Teresina: EDUFPI, 2017.

GANDARA, Gercinair Silvério. Rio Parnaíba... Cidades-beira. 2008. 397 f. Tese (Doutorado em História). Universidade de Brasília.

LIMA, Antônia Jesuíta de. As multifaces da pobreza: forma de vida e representações simbólicas dos pobres urbanos. Teresina: Halley, 2003.

MATOS, Maria Izilda Santos de. As mulheres e a cidade: cotidiano e trabalho (1890- 1920). In: ODÁliA, Nilo; CASTRO, João Ricardo de. (Org.). História do Estado de São Paulo. São Paulo: UNESP, 2010.

MATOS, Maria Izilda S. de. Cotidiano e cultura: história, cidade e trabalho. São Paulo: EDUSC, 2002.

MONTE, Regianny Lima. A cidade esquecida: (res) sentimentos e representações dos pobres em Teresina na década de 1970. 2010. 235 f. Dissertação (Mestrado em História). Universidade Federal do Piauí, Teresina.

NASCIMENTO, Francisco Alcides do. Cajuína e cristalina: as transformações espaciais vista pelos cronistas que atuaram nos jornais de Teresina entre 1950 e 1970. In: Revista Brasileira de História. São Paulo, vol. 27, n.53, p. 195-214, 2007.

. O olhar do outro sobre os pobres urbanos de Teresina na década de 1970. In: X ENCONTRO NACIONAL DE HISTÓRIA ORAL, 10, Recife. Anais do X Encontro Nacional de História Oral Testemunhos: História e Política. Recife: UFPE, 2010. 


\title{
YASMINN ESCÓRCIO MENESES DA SILVA \\ MARCELO DE SOUSA NETO
}

\begin{abstract}
. Teresina, a capital que nasceu sob o signo do moderno e da pobreza. In: XXVI SIMPÓSIO NACIONAL DE HISTÓRIA, 26, São Paulo. Anais do XXVI Simpósio Nacional de História. São Paulo: USP, 2011.
\end{abstract}

PIAUÍ. Mensagem do Governador Alberto Tavares Silva encaminhada à Assembleia Legislativa em 1972. Teresina, mar. 1972.

PESAVENTO, Sandra Jatahy. Cidades visíveis, cidades sensíveis, cidades imaginárias. In: Revista Brasileira de História. v. 27, n. 53. São Paulo, p. 11-23, 2007.

VIANA, DÉBORA SILVA. Entre o concreto e o etéreo: trabalho e memória dos trabalhadores da construção civil em Teresina na década de 1970. 2013. 281 f. Dissertação (Mestrado em História). Universidade Federal do Piauí, Teresina.

SILVA, Yasminn Escórcio Meneses da. "O colorido das lavadeiras": a condição social das lavadeiras de roupas nos rios de Teresina na primeira metade da década de 1970. Monografia (Graduação em Licenciatura Plena em História). Teresina, Universidade Federal do Piauí, 2017.

\section{Entrevistas}

ALVES, Rosa Maria da Costa. Entrevista concedida à Yasminn Escórcio. Teresina, 2017.

DIAS, Maria Francisca Pereira. Entrevista concedida à Débora Silva Viana. Teresina, 2011.

\section{Jornais}

A DURA vida das lavadeiras. Jornal O Dia. Teresina, n 3.826, p. 5, 27/28 jan. 1974.

A MENDINCÂNCIA em Teresina: as lavadeiras do Parnaíba. Estado do Piauí. Teresina, ano 47. n. 1387 , p. 1,19 ago. 1971

EDIÇÃO especial. Caderno 2. Jornal O Estado. Teresina, s/n, p. 6, 6 fev. 1975.

FATOS e destaques: Lavandeiras. Jornal A Hora. Teresina, n. 148. p. 6, 7 abr. 1972.

O DRAMA da migração. Jornal O Estado. Teresina, ano 705, p. 10, 27 fev. 1975.

O GOVERNO construirá lavanderias. Jornal do Piauí. Teresina, ano 20, n. 3.383, p. 1,16 jul. 1971. 